\title{
Neck Dissection - Techniques and Complications
}

\author{
Jaimanti Bakshi ${ }^{1}$, Naresh K. Panda², \\ Abdul Wadood Mohammed ${ }^{3}$ and Anil K. Dash ${ }^{4}$ \\ ${ }^{1}$ Dept. Of Otolaryngology\&HNS, PGIMER, CHANDIGRH \\ ${ }^{2}$ Dept. Of OtolaryngologyEHNS, PGIMER, CHANDIGARH \\ ${ }^{3}$ Dept. Of OtolaryngologyEHNS, PGIMER \\ ${ }^{4}$ Dept. Of Otolaryngology\&HNS, PGIMER, CHANDIGARH \\ India
}

\section{Introduction}

"Neck dissection" refers to the surgical procedure where the lymphatics and the fibro fatty tissue of neck are removed as a treatment for cervical lymphatic metastasis. As malignancies of the upper aero-digestive tract mainly metastasize to the cervical lymph nodes, neck dissections are performed along with surgical excision of these malignancies.

\section{Relevant anatomy}

The cervical lymph nodes are surgically divided into six levels. Each level of lymph node is interconnected by lymphatic channels and drain specific anatomic sites of the aerodigestive tract.

Level 1a - sub-mental group

It is the midline group bounded on both sides by the anterior belly of digastrics and the hyoid bone inferiorly. Tumors of floor of mouth, anterior oral tongue, anterior mandibular alveolar ridge, and lower lip metastasize to these nodes.

\section{Level $1 \mathbf{b}$ - submandibular group}

These are the lymph node groups bounded by the anterior and posterior belly of digastric and mandible superiorly. The submandibular gland is usually included in the specimen when this group of lymph nodes is removed. Cancers of oral cavity, anterior nasal cavity, soft tissue structures of mid face and submandibular gland commonly metastasize to this group of lymph nodes.

\section{Level $2 a$ and $2 b$ - upper jugular group}

This group of lymph nodes is related to the upper $1 / 3^{\text {rd }}$ of the internal jugular vein. They are bounded by the skull base above, inferior border of hyoid bone below, lateral border of sternohyoid and stylohyoid anteriorly and posterior border of sternocleidomastoid posteriorly. This group is further divided by the vertical plane in relation to the spinal accessory nerve. Level $2 a$ is anterior to this plane and level $2 b$ is posterior. Cancers of oral 
cavity, nasal cavity, nasopharynx, oropharynx, hypopharynx, larynx and parotid gland mainly metastasize to this group.

Level 3 - middle jugular group

These lymph nodes are related to the middle $1 / 3^{\text {rd }}$ of the internal jugular vein. This level is bounded by inferior border of hyoid bone above, inferior border of cricoid cartilage below, lateral border of sternohyoid anteriorly and posterior border of sternocleidomastoid posteriorly. Cancers of oral cavity, nasopharynx, oropharynx, hypopharynx, and larynx metastasize to this group of lymph nodes.

Level 4 - lower jugular group

This group of lymph nodes is related to the lower $1 / 3^{\text {rd }}$ of internal jugular vein. They are bounded by the lateral border of sternohyoid anteriorly, posterior border of sternocleidomastoid posteriorly, inferior border of cricoid cartilage superiorly and the clavicle inferiorly. Cancers from hypopharynx, cervical esophagus and larynx metastasize to this level.

Level $5 \mathbf{a}$ and $5 b$ - posterior triangle group

This group of lymph nodes is related to the lower $1 / 3^{\text {rd }}$ of the internal jugular vein along the lower half of the spinal accessory nerve and the transverse cervical artery. They also included the supraclavicular group of nodes. They are bounded by the posterior border of sternocleidomastoid anteriorly, anterior border of trapezius posteriorly and inferiorly the clavicle. Sublevel $5 \mathrm{a}$ and $5 \mathrm{~b}$ are separated by a horizontal plane marking the inferior border of arch of the cricoid cartilage. Cancers of the nasopharynx, oropharynx and the thyroid gland mainly metastasize to this group.

Level 6 - anterior compartment group

This group includes the pre and para tracheal nodes, the precricoid (Delphian) and the perithyroidal nodes. They are bounded by hyoid bone superiorly, supra sternal notch inferiorly and common carotid arteries laterally. Cancers arising from the thyroid gland, glottic and subglottic larynx, apex of pyriform sinus and cervical esophagus mainly metastasize to this group of lymph nodes.

\section{History}

- In 1888, Jawdynski described en bloc resection of cervical lymph nodes with resection of carotid, internal jugular vein and sternocleidomastoid muscle which was associated with very high rate of mortality.

- In 1906, George W. Crile of the Cleveland Clinic described the radical neck dissection. The operation encompasses removal of all the lymph nodes on one side along with the spinal accessory nerve, internal jugular vein and sternocleidomastoid muscle.

- In 1967 - Oscar Suarez and E. Bocca described a more conservative operation which preserves spinal accessory nerve, internal jugular vein and sternocleidomastoid muscle which further improved the quality of life of patients post operatively.

\section{Classification of neck dissections}

The classification proposed by the Committee for head and neck surgery and oncology of the American Academy of Otolaryngology and Head and Neck surgery is the first 
comprehensive classification widely accepted. It is based on the rationale that radical neck dissection is the standard basic procedure for cervical lymphadenectomy, and all other procedures represent one or more modifications of this procedure. When the modification of the radical neck dissection involves preservation of one or more non-lymphatic structures, the procedure is termed a modified radical neck dissection, when the modification involves preservation of one or more lymph node groups that are routinely removed in the radical neck dissection; the procedure is termed a selective neck dissection and when the modification involves removal of additional lymph node groups or non-lymphatic structures relative to the radical neck dissection, the procedure is termed an extended radical neck dissection.

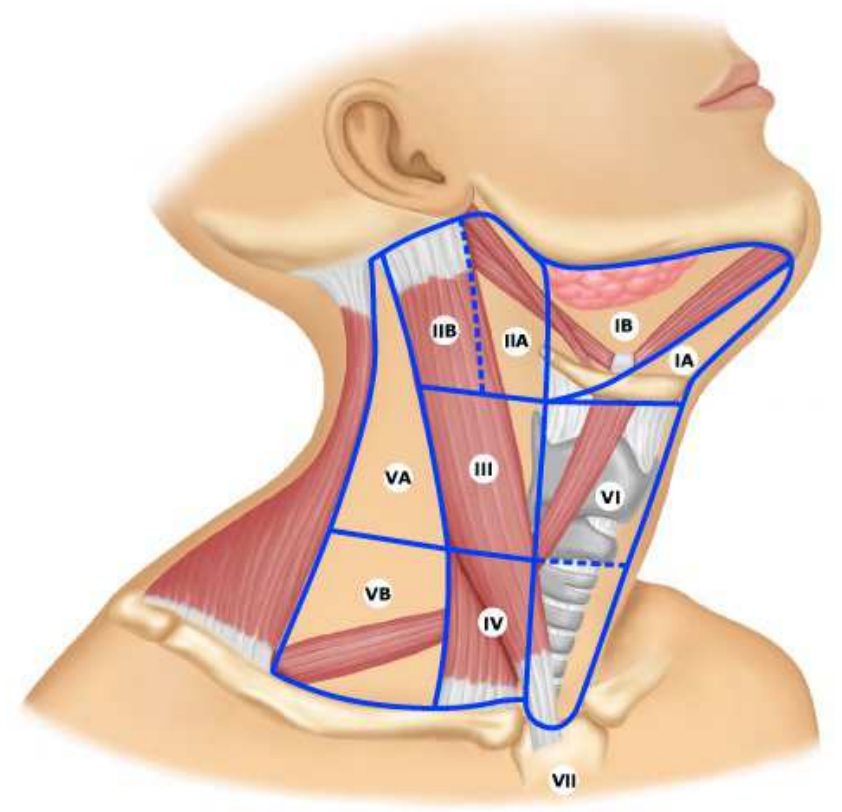

Fig. 1. Lymph node levels of neck

Medina et al has suggested that the term"comprehensive neck dissection" be used whenever all of the lymph nodes contained in levels I through $\mathrm{V}$ have been removed. Hence, the radical neck dissection and modified radical neck dissection would each be considered a comprehensive neck dissection.

Three subtypes of modified radical neck dissection were recommended to denote which of the three non lymphatic structures were removed. The neck dissection is labeled as type 1 , when only spinal accessory nerve is preserved, type 2 when spinal accessory nerve and the internal jugular vein was preserved and type 3 when all three non lymphatic structures were preserved. Spiro et al also have suggested changes to the existing Academy's classification system. He used the term radical neck dissection when 4 or 5 levels are resected, which included conventional radical neck dissection, modified radical neck dissection and extended radical neck dissection. The term selective neck dissection was used when 3 levels of lymph nodes are dissected and limited neck dissection when no more than 2 levels of lymph nodes are dissected. 


\section{Surgical procedure:}

Radical Neck Dissection: Procedure is done under general anesthesia. Position the patient in reverse Trendelenberg's position with neck extended at atlanto-axial joint and head elevated 10 degree above the table. Face should be turned to the opposite side of the dissection. Neck skin should be cleaned with Betadine scrub and after that with 3 layers of Betadine solution. Drap the operating site with sterile towels over a polydrape sheet to minimize the infection rate. Our preferred incision for R.N.D. is Lahey's lateral utility incision in post-irradiated patients. Modified Schobinger's incision has been found to be useful in patients undergoing commando operation. We are using Mc fees double horizontal incision in some selected post-irradiated cases.

Incision is marked with surgical marker pen, infiltrate with $10-15 \mathrm{ml}$ of $1 \%$ xylocaine with 1:4 lacs adrenaline solution. Wait for 5 minutes, make skin incision with 10 number surgical blade, raise the sub-platysmal flap superiorly till lower border of mandible, mastoid tip posteriorly, midline of neck anteriorly, anterior border of trapezius posteriorly, and till clavicle inferiorly. Then the lower part of sterno-cliedomastiod muscle is cut with electrocautery, $2 \mathrm{cms}$ above clavicle after dissecting it carefully from internal jugular vein. Dissect the IJV from its fascial attachments with common carotid artery and vagus nerve. The lower end of IJV is ligated at level of common tendinous attachment of 2 bellies of omo-hyoid muscle crossing over IJV. Transfix the IJV after ligating with double ligatures. Pull the IJV up gradually with SCM muscle after holding with Babcock forceps. Dissect all lymph nodes, lymphatics,fat and fascia from the supra clavicular fossa including level 5 nodes. Take care not to damage the brachial plexus, phrenic nerve, transverse cervical vessels. At the junction of upper $1 / 3$ and lower $2 / 3$ of SCM muscle, greater auricular nerve,can be seen exiting from cervical plexus crossing over external jugular vein along posterior border. GAN winds around the posterior border of SCM muscle and crosses obliquely upwards to enter into the tail of parotid gland. Spinal accessory nerve also exits at this point, known as Erb's point and runs in the posterior triangle to enter into trapezius muscle. These nerves have to be dissected from cutaneous branches supplying the fascia and skin. Ligate middle thyroid vein at level of thyroid cartilage and remove all lymph nodes along the middle $1 / 3$ of IJV thus clearing level $3 \& 4$. Now, we have reached at the upper end of IJV. Dissect at the level of posterior belly of digastric muscle which is the landmark for ligating the upper end. Bony landmark is the transverse process of atlas. Ligate with double ligatures, transfix with 3-0 silk suture and cut the IJV after ligating the venae commitante for hypoglossal nerve. This will clear level $2 \mathrm{a} \& 2 \mathrm{~b}$ lymph nodes. Last step is removal of level 1a \& $1 \mathrm{~b}$ nodes along with submandibular gland. Remove the complete specimen enbloc. Irrigate the dissected field with normal saline and dilute betadine solution. After securing hemostasis, put Romovac 14-16 FG size drain, fix it with braided silk sutures, and connect to the bellow. After repositing the skin flap, first layer is sutured with 3-0 vicryl/ catgut suture and skin with staples /3-0 Ethicon monocryl sutures. Apply pressure dressing and check the drain function before extubating the patient. Post opetatively, patient is kept in fowler's position and give I.V. antibiotics for 5 days. Remove drain when collection is $<10 \mathrm{ml}$. Remove sutures on $7^{\text {th }}$ post operative day. Discharge the patient on $7^{\text {th }}$ day. Follow up will be after 1 week, check the histopathology report to see how many lymph nodes were dissected and the number of positive nodes. Refer for radiotherapy if needed. Thereafter at 1 month. Contrast CT scan /PET-CT scan should be ordered at 6 month follow up for recurrent disease. One monthly follow up will continue for 1 year ,thereafter 3 monthly for 2 years and then yearly for 10 years. 


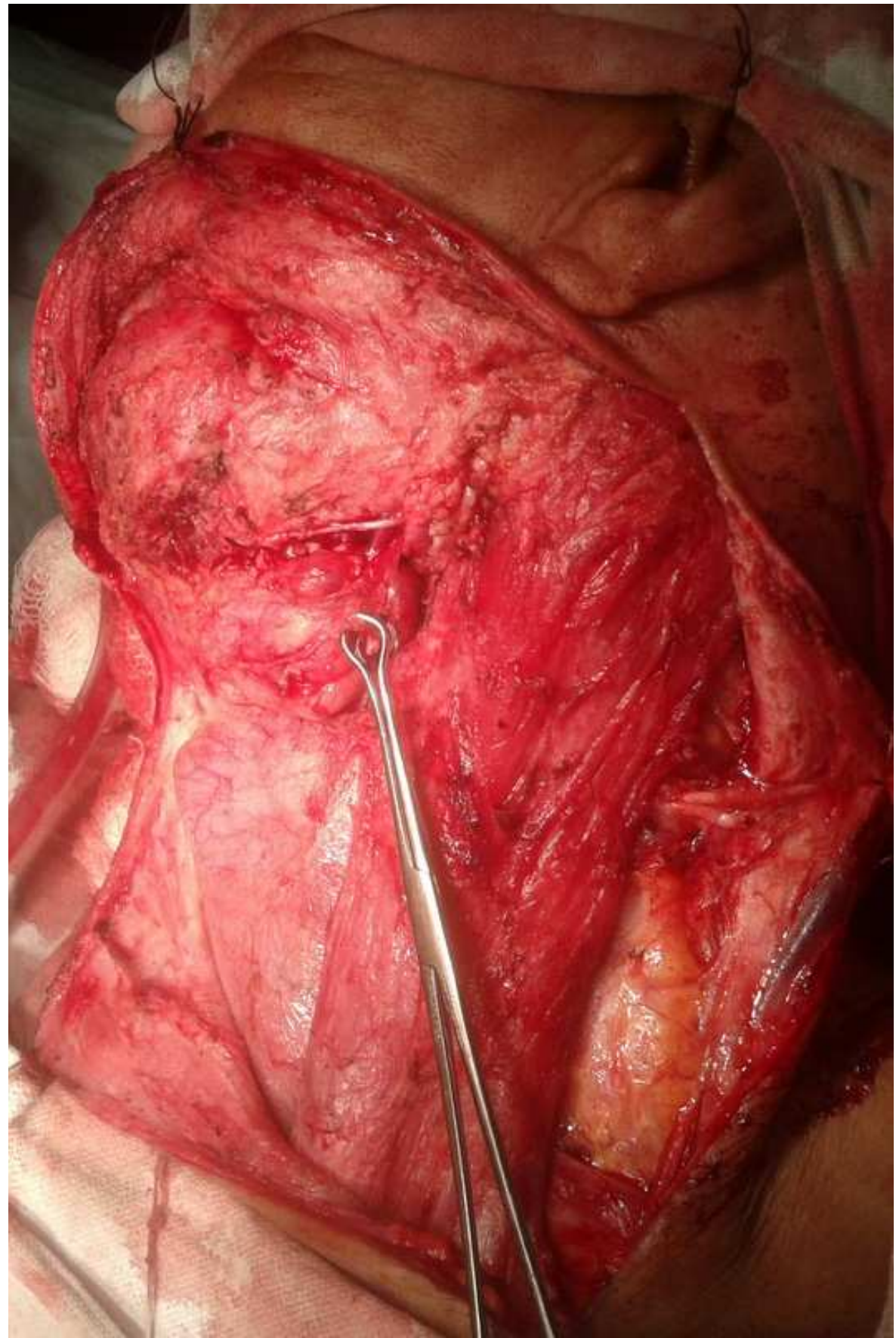

Fig. 2. Neck dissection showing left level II lymph node adherent to IJV 


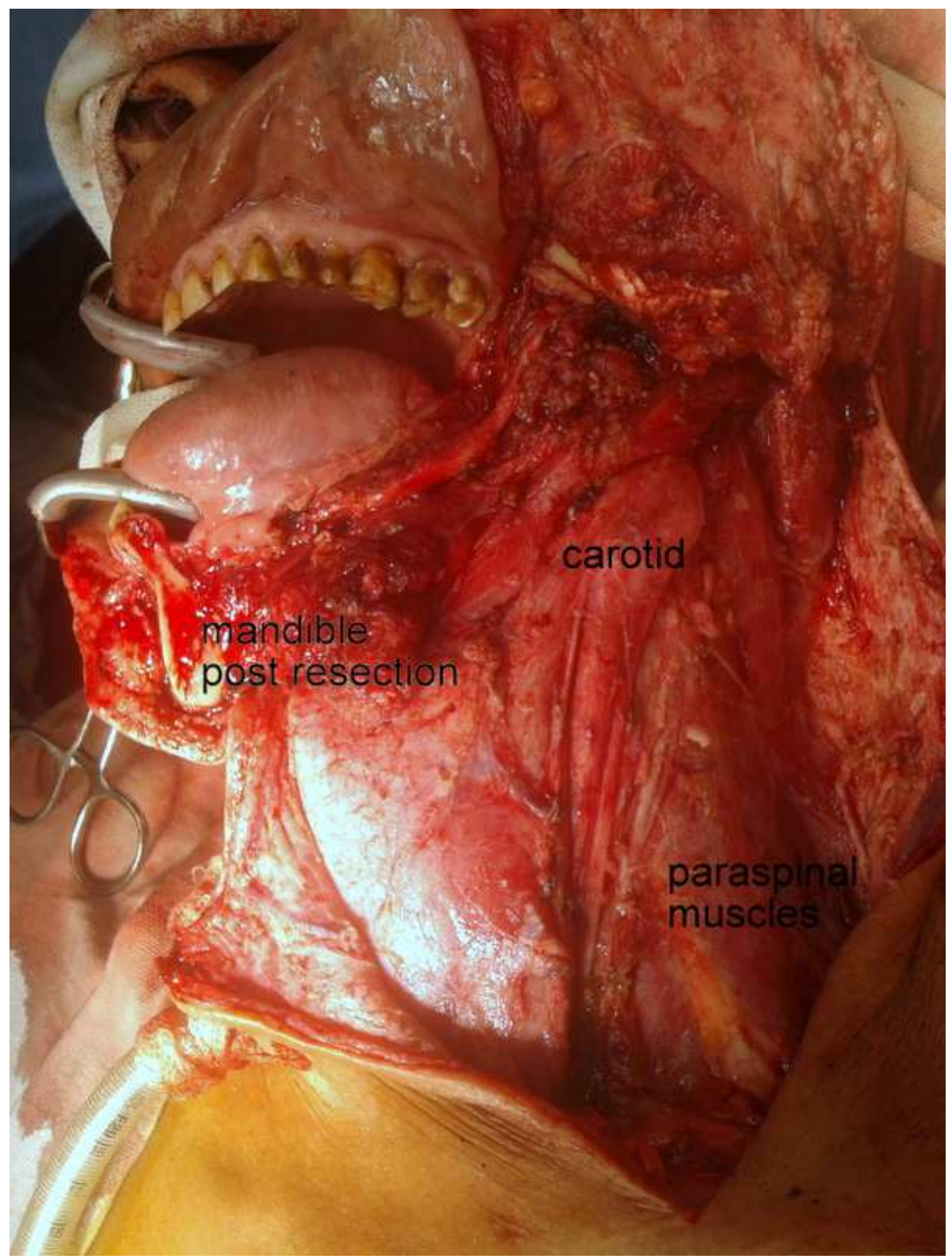

Fig. 3. Commando operation showing left radical neck dissection

\section{Modified Neck Dissection:}

The basic procedure will remain same as for RND but we have to preserve one/more than one of the 3 structures i.e. SCM muscle, Spinal accessory nerve and IJV. Preserve the greater auricular nerve and transverse cervical vessels for decreased morbidity. 


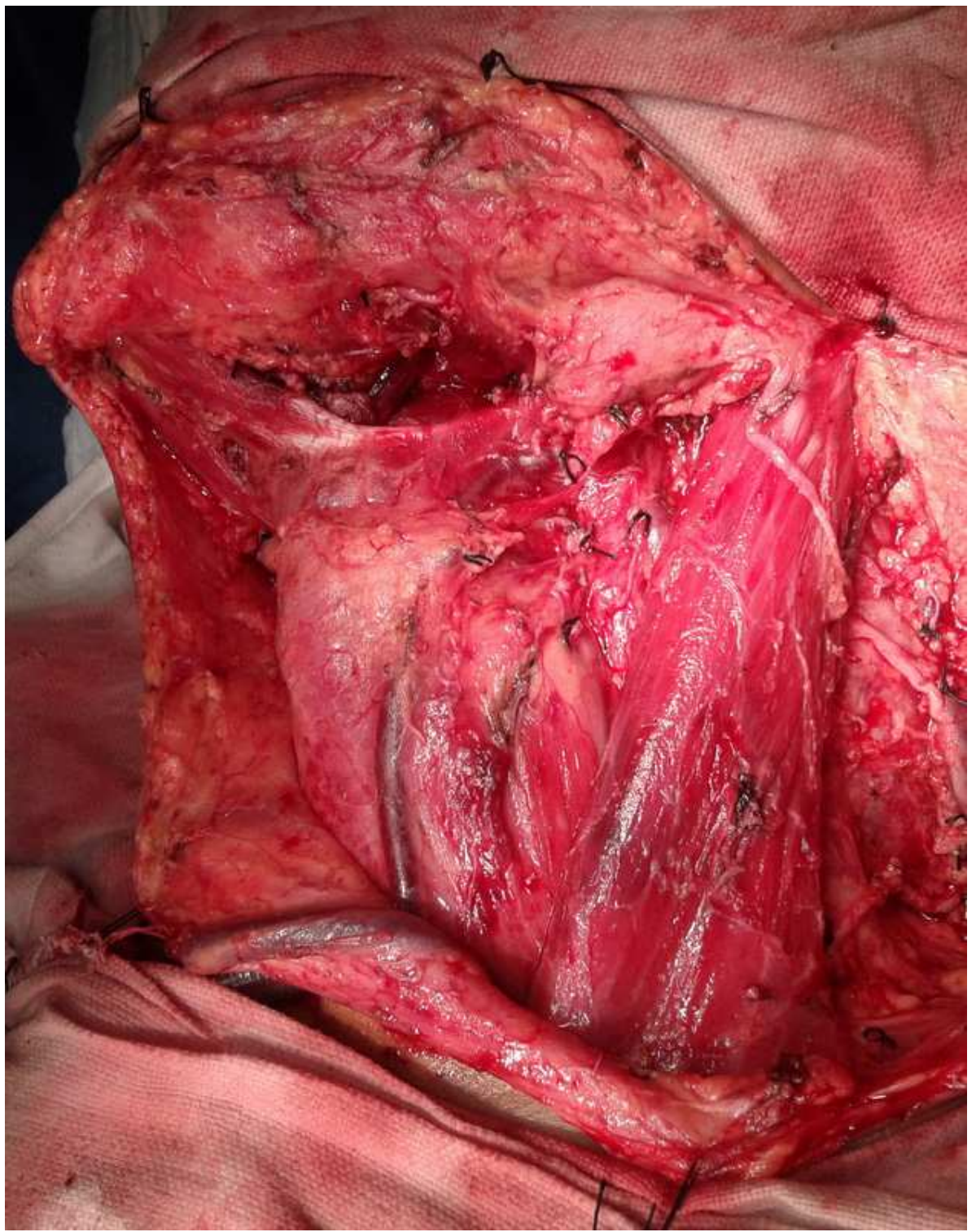

Fig. 4. Post Modified Radical Neck Dissection on Left side 


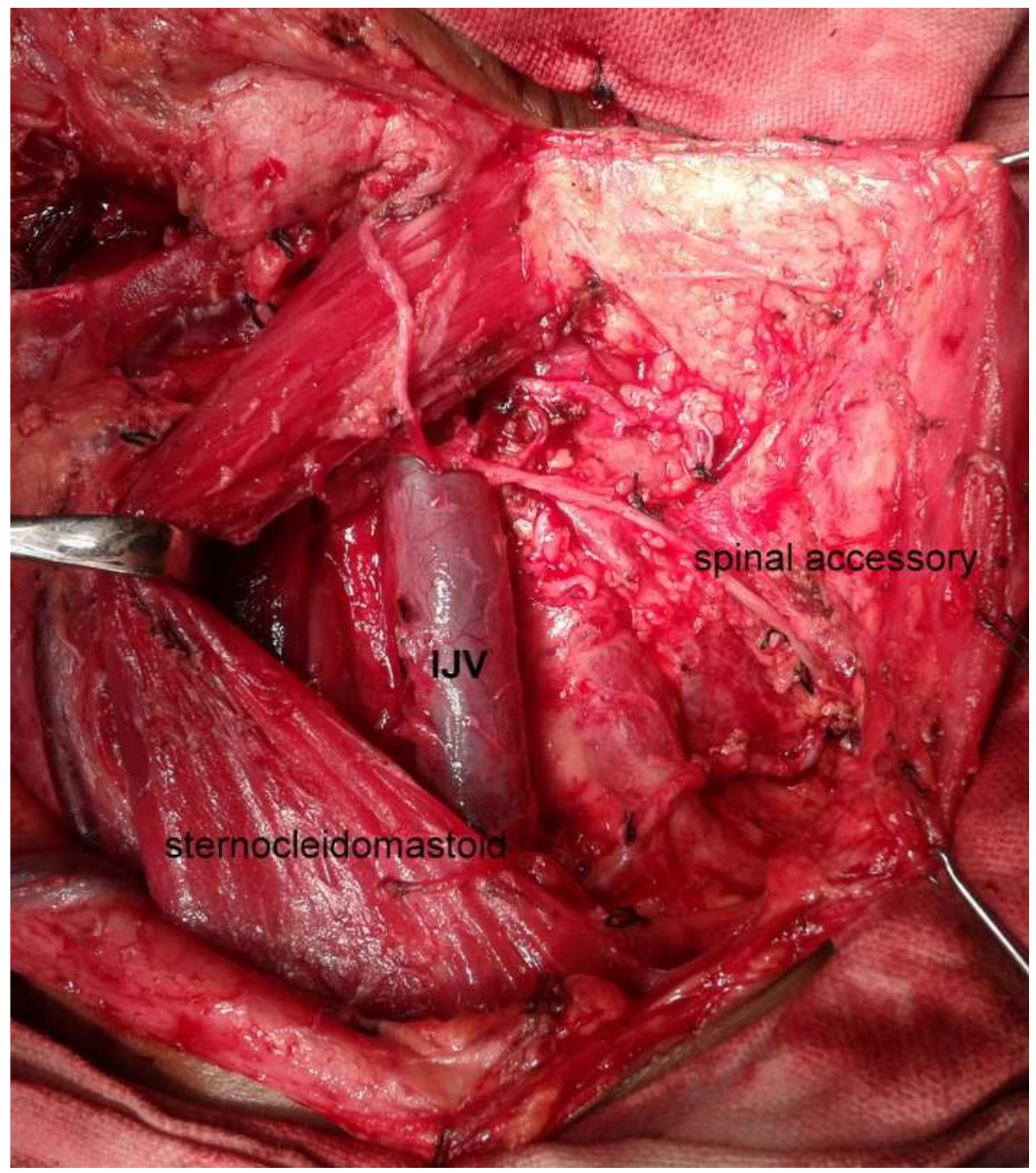

Fig. 5. Left Modified Radical Neck dissection exposing preserved structures

\section{Selective Neck Dissection:}

Modified Schobinger incision/ Apron flap incision are the best incisions for this procedure. Dissection will start from level I and will go to level III/IV in Supra omohyoid neck dissection and will include level VI in Anterior compartment dissection. 


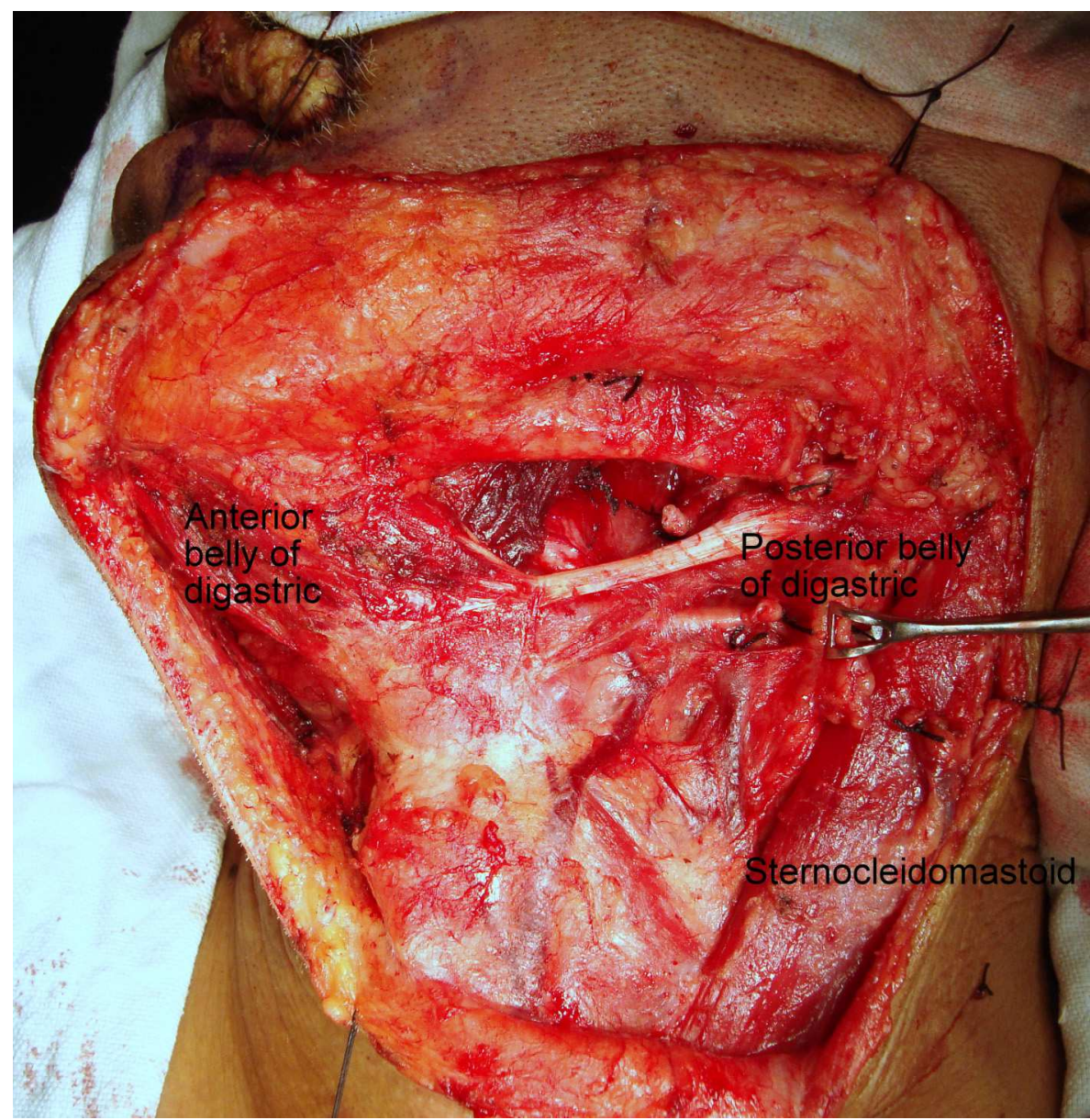

Fig. 6. Post left supra-omohyoid neck dissection

\section{Our experience}

Type 3 Modified neck dissections and selective neck dissections are the most common neck dissections performed in our institute. The decision is made intra operatively. In general,for N0 neck, supraomohyoid neck dissection and for N1 neck, type 3 modified radical neck dissection is done. Radical neck dissection is done only when there is gross infilteration of the sternocleidomastoid muscle or spinal accessory nerve or internal jugular vein intra operatively or in post irradiated neck. 
Modified schobinger's incision is the most common incision used for Modified radical neck dissection. It has the advantage of adequate exposure and the incision can be easily extended anteriorly as lip splitting incision in order to expose the primary oral cavity tumor. The Lahey's lateral utility incision is commonly used in post irradiated neck as it has the advantage of not forming a three point junction and prevents wound dehiscence and carotid blow out. Transverse cervical neck incision would suffice for supra omohyoid neck dissection. Other incisions occasionally used are the Wisor flap, Boomerang incision and Mc fee's incision. Post operatively negative suction drains are put for an average period of 3-5 days and patient needs hospital admission for an average period of 10 days. Plan for post operative radiotherapy is done according to the stage of disease and post operative histopathology report. External Beam radiotherapy is given in the dose of 50 to 55 Grays in 20 to 30 fractions with in a period of 6 weeks started as early as possible when the wound is healed. Radiotherapy is given for all advanced stage disease (Stage 3 and 4) and when the histopathology report shows resection margins involved or close to tumour, more than 2 lymph nodes involved, perineural spread or extracapsular spread.

Figures 7, 8, 9 show the types of incisions which we use for neck dissections.

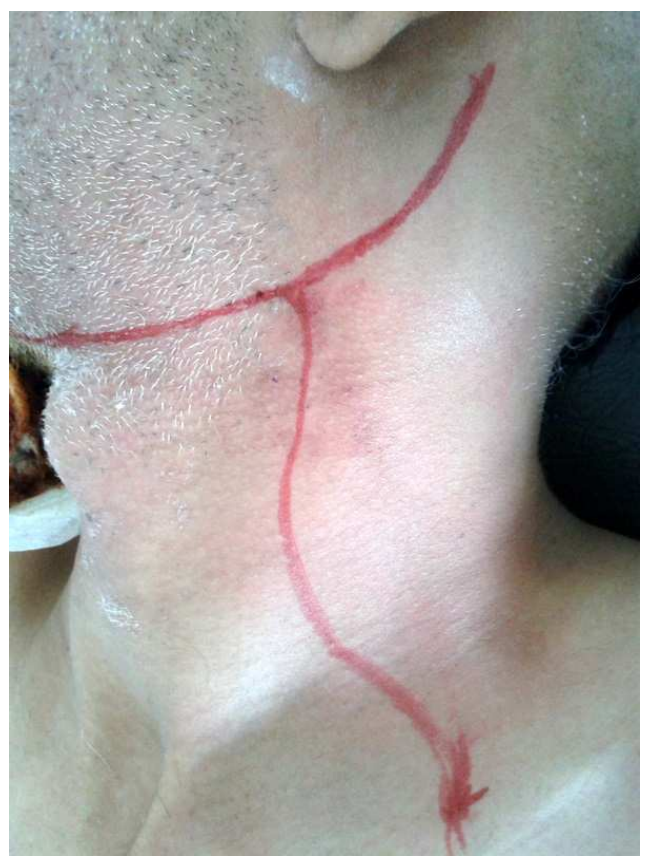

Fig. 7. Modified Schobinger's incision 


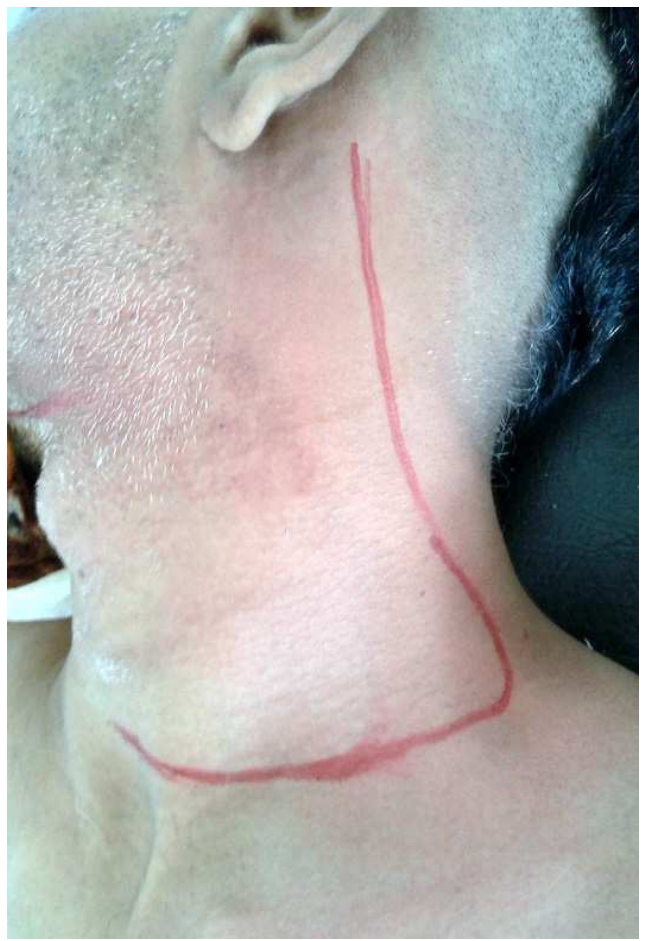

Fig. 8. Lateral Utility incision Lahey's

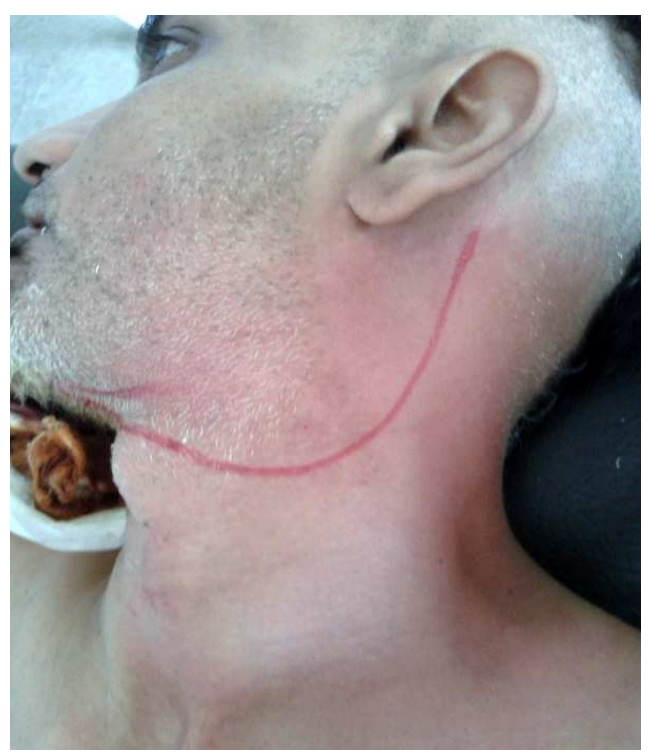

Fig. 9. Apron flap incision 


\section{Complications}

1. Anesthesia of the skin of the neck is most common complication.

2. Black/ bluish discoloration of the skin flap at 3 point junction or at posterior lip can occur in some patients.

3. Minor wound dehiscences and wound infections can occur in some.

4. Seroma formation has been seen occasionally.

5. Chyle leak can occur in 2-3\% patients and heals with conservative treatment most of the times. No patient required neck exploration for repair of the thoracic duct.

6. Air embolism can occur in $<1 \%$ cases due to inadvertent injury to IJV.

7. Carotid blow out has been seen in $<1 \%$ patients after RND. It is common in irradiated necks

\section{Case 1}

32 year old male presented to our out patient department with complaints of non healing ulcer over the tongue for which he was taking medication from local practisioners. He had been taking Gutka (a local tobacco preparation) and was smoking cigarettes around cigarattes 2 - 3 packs / day for 15 years. On examination he had a $2 \times 2 \mathrm{~cm}$ ulcero indurated lesion over the right lateral border of tongue. His neck examination showed a $1 \times 1.5 \mathrm{~cm}$ right level $1 \mathrm{~b}$ lymph node. A PET/CT was done for metastatic work up which showed intense uptake over the lesion on the right lateral border of tongue, moderate uptake in right level $1 \mathrm{~b}$ and 2 lymph nodes and no distant metastasis. Patient underwent right partial glossectomy with right type 3 functional neck dissection. The post operative histopathology report came as all resection margins free of tumor, however the posterior resection margin was close to tumor and 0/33 lymph nodes free of tumor. Patient underwent post operative external radiotherapy of 55 Gys 25 fractions in 6 weeks and is now on follow up for the last 6 months without any locoregional recurrence.

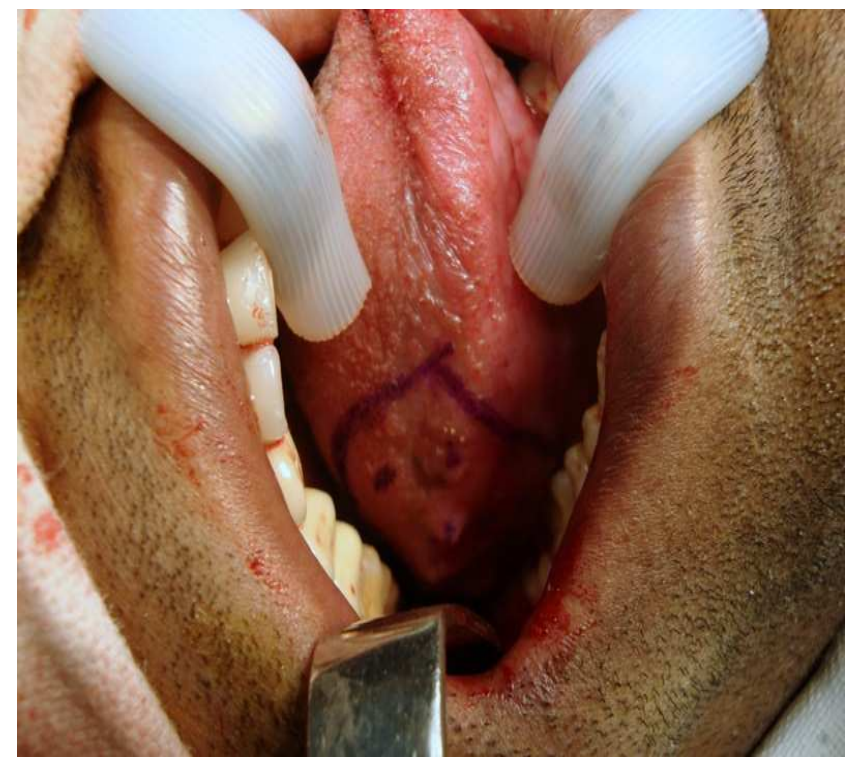

Fig. 10. Ulcero indurated growth involving right lateral border of tongue 


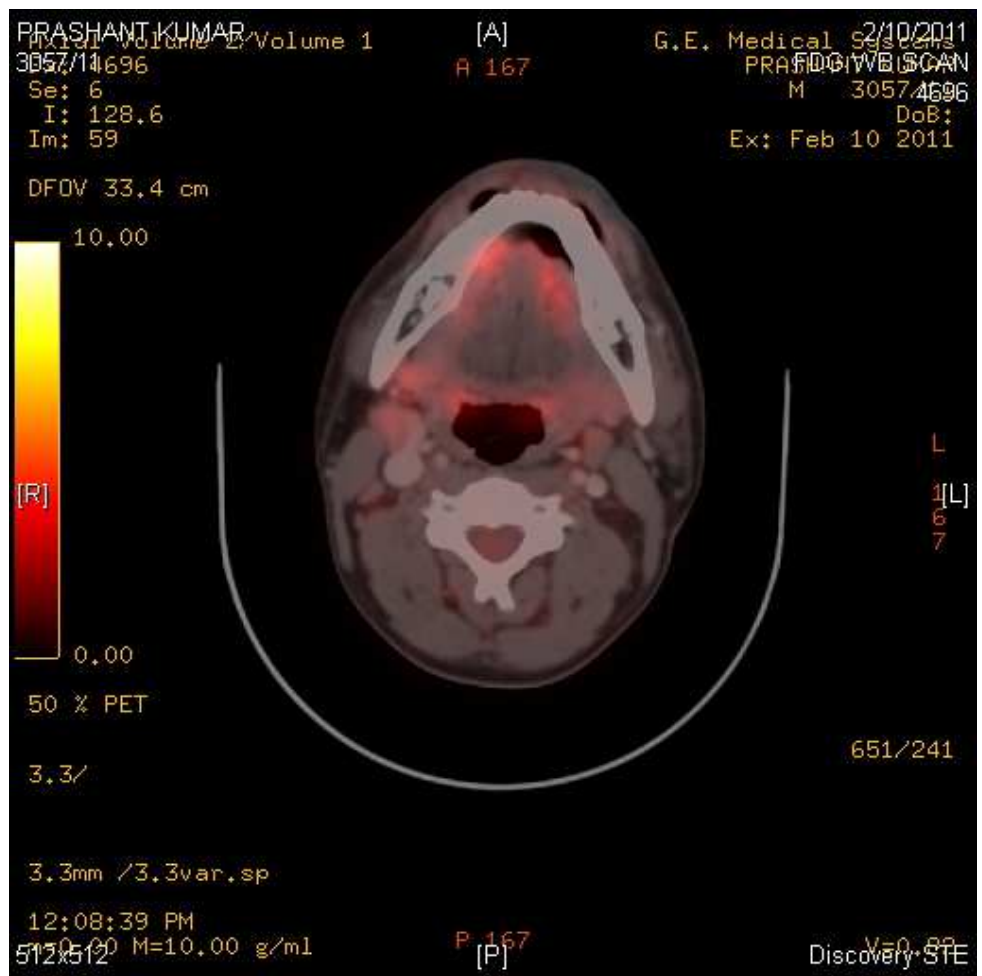

Fig. 11. PET/CT showing increased uptake in right lateral border of tongue and Right level $1 \mathrm{~b}$ and 2 lymph nodes

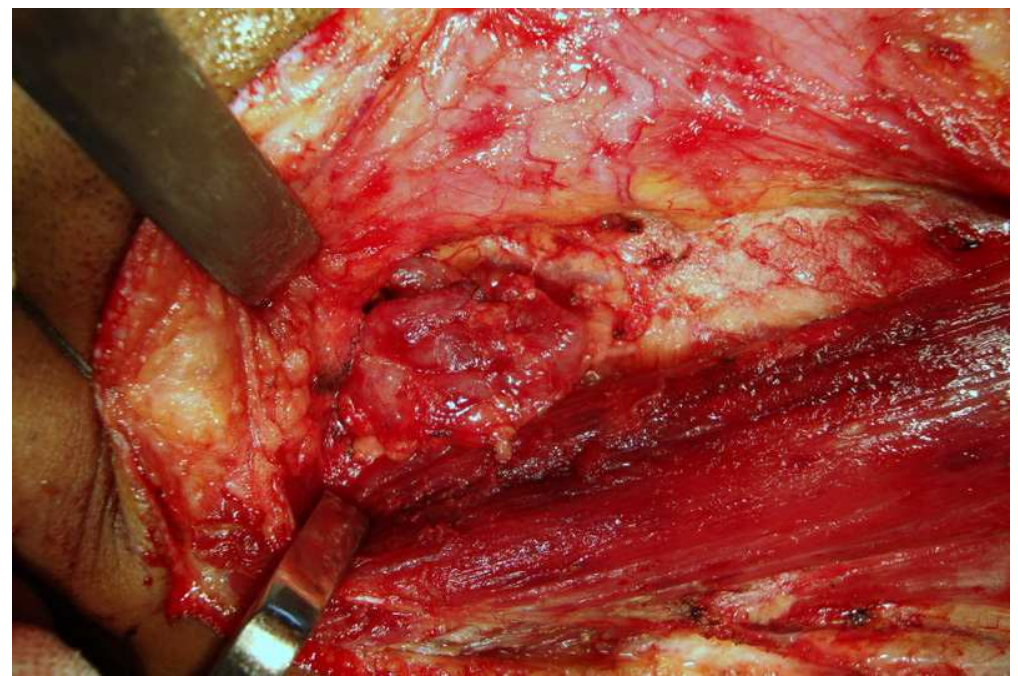

Fig. 12. Right level 1b lymph node 


\section{Case 2}

50 year old chronic Zarda chewer (local tobacco preparation) and cigarette smoker presented with growth over the left lower alveolus for 3 months. On examination he had a 4 $x 3 \mathrm{~cm}$ ulcero proliferative growth extending from the (L) lateral incisor to the $3 \mathrm{rd}$ molar involving the lower gingivo buccal sulcus and the buccal mucosa till the level of crown of teeth. There was a $3 \times 3 \mathrm{~cm}$ swelling over the left mandible $1 \mathrm{~cm}$ away from the angle of mouth with free overlying skin. On neck examination the left level $1 \mathrm{~b}$ had $1 \mathrm{x} 1 \mathrm{~cm}$ lymph node and level $23 \times 2 \mathrm{~cm}$. A PET/CT was done for metastatic work up which showed intense uptake SUV 22.3 over the lesion over (L) lower alveolus and (L) level $1 \mathrm{~b}$ and 2 without any distant metastasis. Patient underwent (L) segmental mandibulectomy with (L) Radical neck dissection as the level 2 lymph node was adherent to the IJV and sternocleidomastoid intra operatively and reconstruction with pectoralis major myocutaneous flap. Patient received 50 Gys External Radiotherapy and is disease free for 12 months.

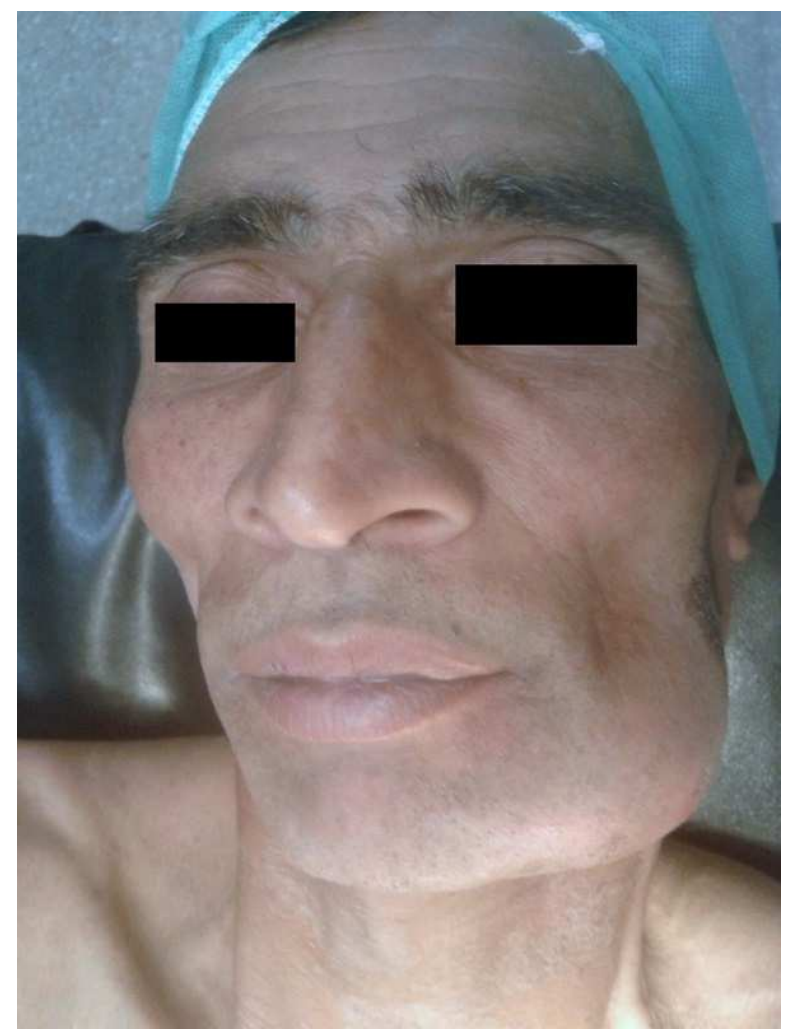

Fig. 13. case 2 


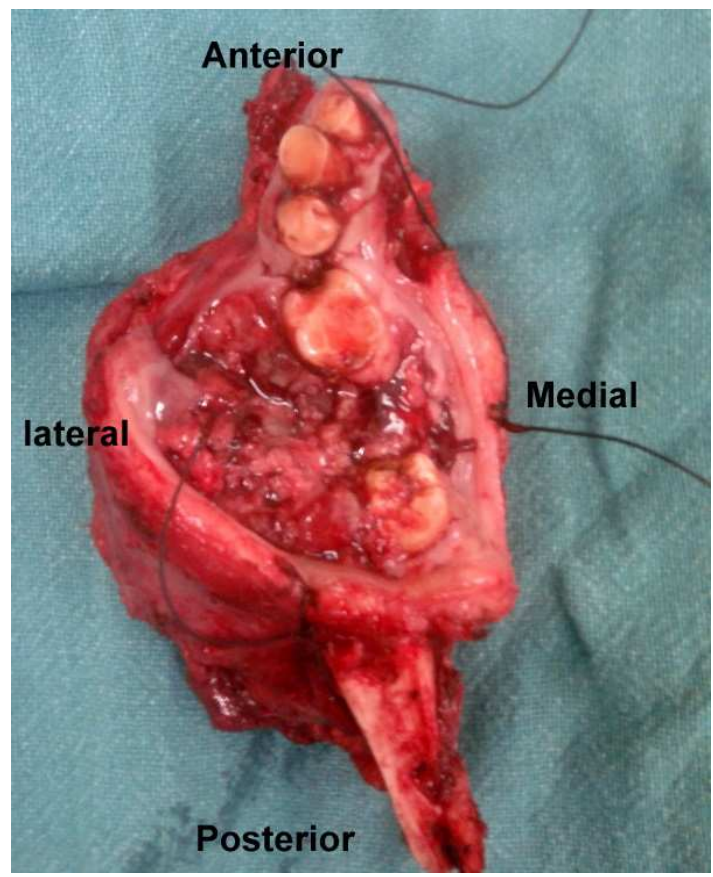

Fig. 14. Segmental mandibulectomy with tumor

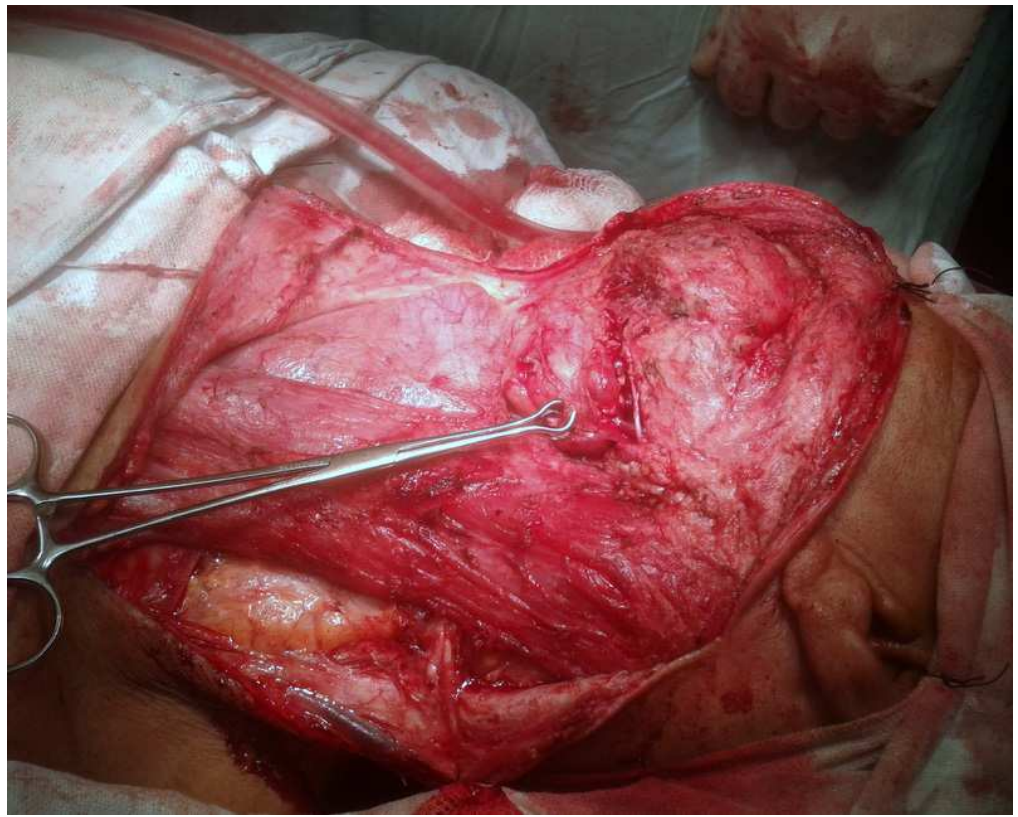

Fig. 15. Neck dissection. Showing Marginal Mandibular nerve and Level Ib lymph node 


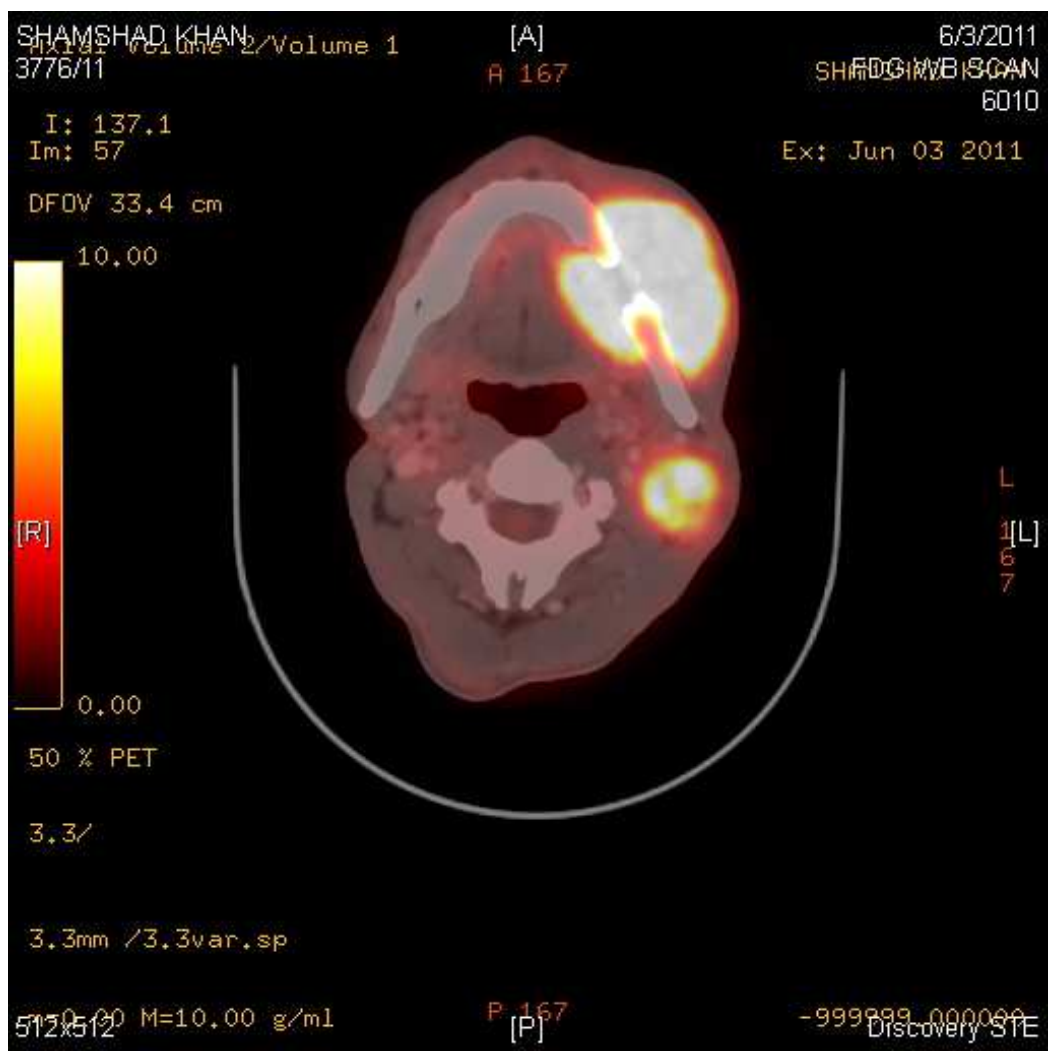

Fig. 16. PET/CT image case 2

\section{Case 3}

37 year old female with no history of any addiction presented with history of swelling over the left cheek which was rapidly increasing in size and difficulty in opening mouth for 3 month. On examination there was a $6 \times 8 \mathrm{~cm}$ swelling over the left cheek which was fluctuant. The swelling late ruptured to form an ulcer as shown in figure 17 . There was a $3 \mathrm{x}$ $3 \mathrm{~cm}$ ulcer in the left buccal mucosa with extension into the lower gingivo buccal sulcus. On neck examination left level $1 \mathrm{~b}$ was $1 \times 2 \mathrm{~cm}$ enlarged. CECT of neck was done which showed the primary tumor involving left buccal mucosa and skin with ipsilateral involvement of level $1 \mathrm{~b}$ and 2 lymph node levels. The patient underwent a Wide local excision with left type 3 modified neck dissection and the defect was reconstructed using antero-lateral thigh free flap. The patient received 60 Gys postoperative radiotherapy over 6 weeks and is disease free for 12 months now. 


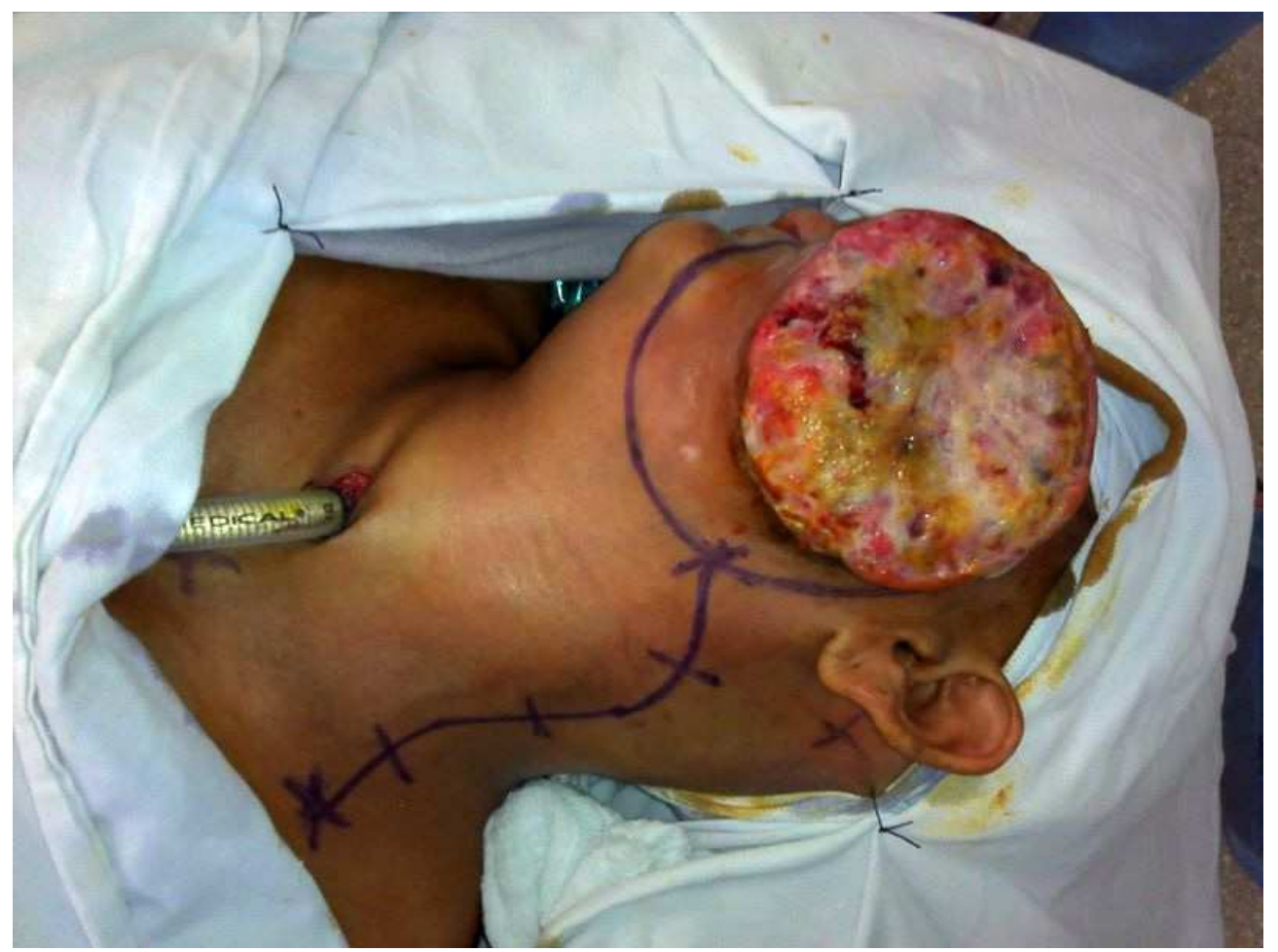

Fig. 17. Primary lesion. Incision is modified for resection of primary tumor 


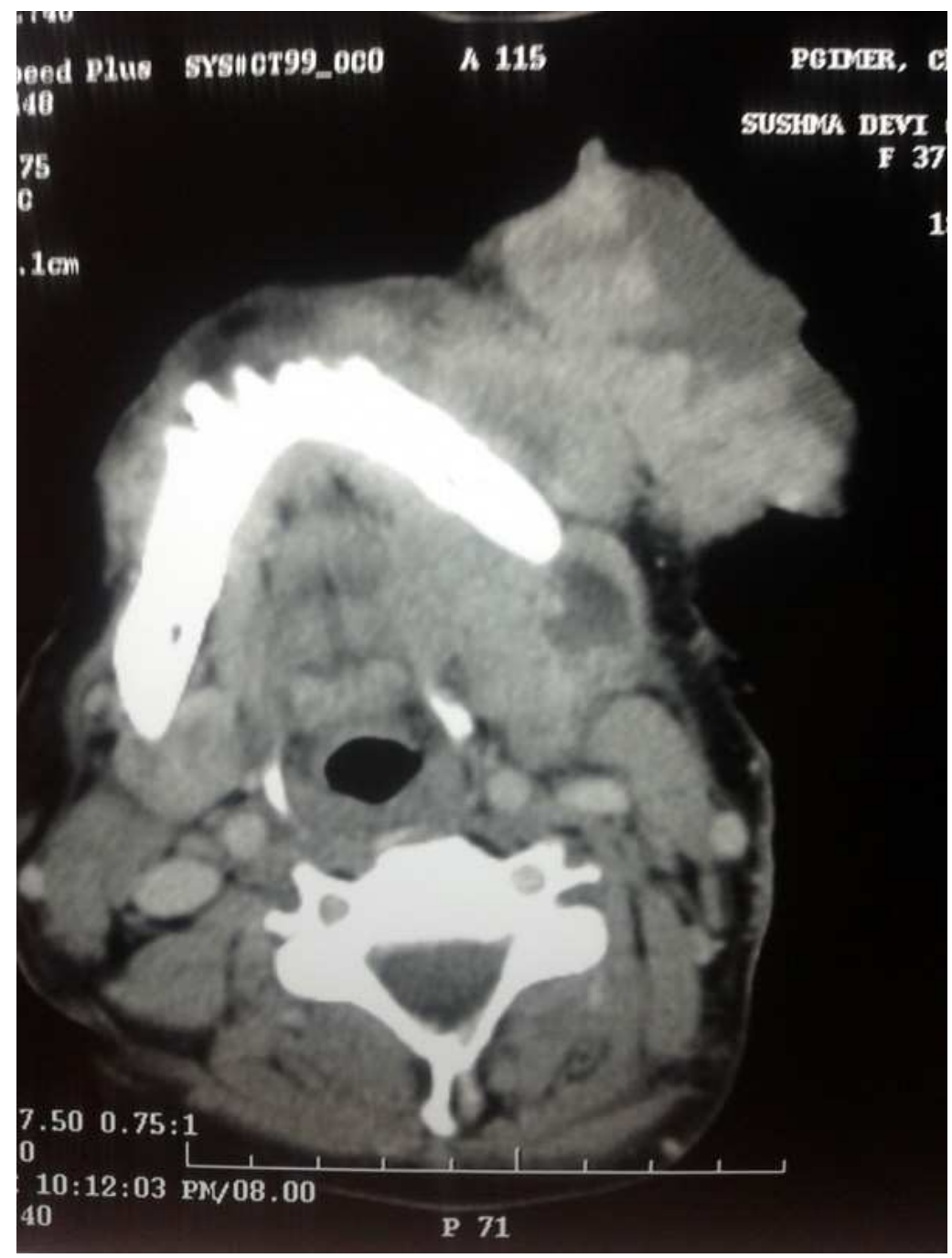

Fig. 18. CECT of case 3 showing primary tumour and neck node 


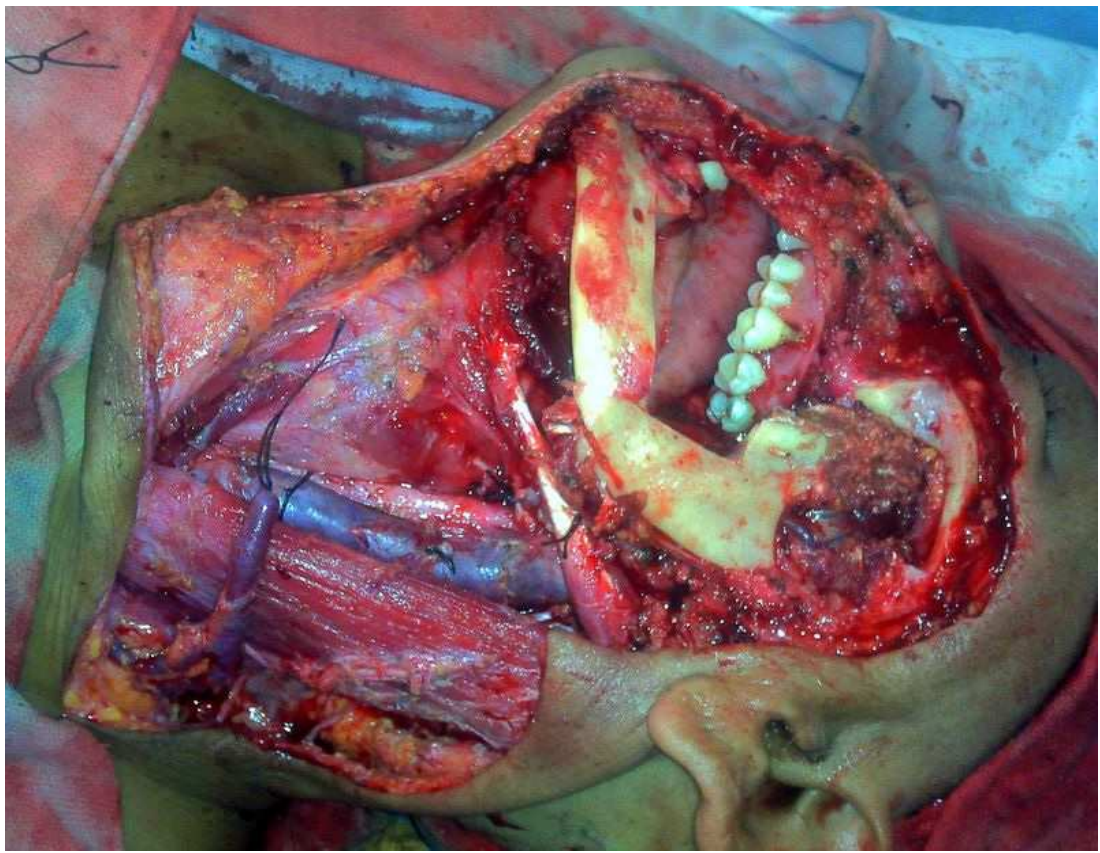

Fig. 19. Post resection with Segmental Mandibulectomy and Modified neck dissection

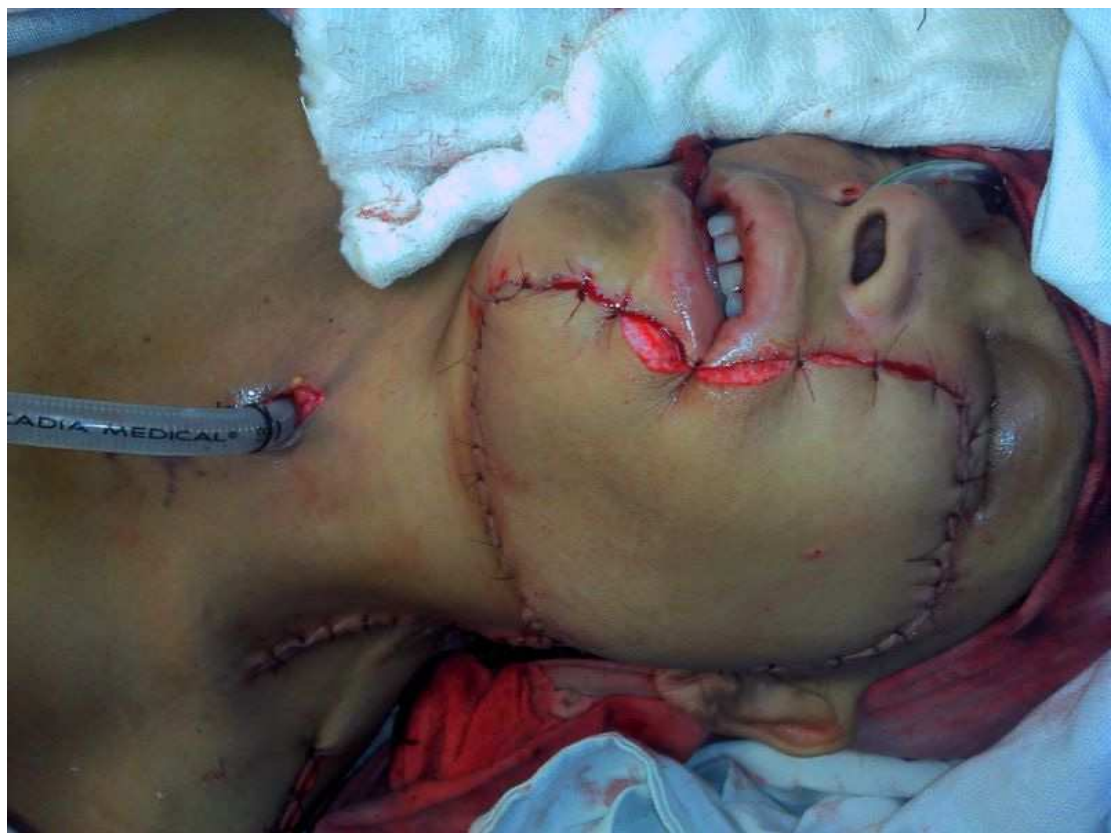

Fig. 20. After reconstruction with Antero lateral thigh free flap 


\section{Complications}

Complications of neck dissection can be broadly divided into early, intermediate and late.

\section{Immediate}

\section{Hemorrhage}

Postoperative hemorrhage usually occurs immediately after surgery. External bleeding through the incision often originates in a subcutaneous blood vessel. In most patients, this may be readily controlled by ligation, direct cauterization or infiltration of the surrounding tissues with an anesthetic solution containing epinephrine. Pronounced swelling or ballooning of the skin flaps immediately after surgery, with or without external bleeding, should be attributed to a hematoma in the wound. If a hematoma is detected early, "milking" the drains occasionally may result in evacuation of the accumulated blood and the problem will resolve. If this is not accomplished immediately or if blood re-accumulates quickly, it is best to return the patient to the operating room, explore the wound under sterile conditions, evacuate the hematoma, and control the bleeding.

\section{Airway obstruction}

In cases of bilateral neck dissections there may be associated soft tissue edema. Moreover resection of the primary upper aero-digestive malignancy may also add to the edema of the airway. It is always prudent to carry out a temporary elective tracheotomy to protect the airway.

\section{Increased intracranial pressure}

This usually occurs when the internal jugular vein is ligated. When one internal jugular vein is ligated the pressure rises by 3 fold and when both are ligated it increases by 5 fold. This usually is temporary and will normalize in 24 hours. If it persists, head end elevation, steroids and mannitol can be used.

\section{Nerve injury}

The main nerves which are at risk during neck dissection are spinal accessory nerve, vagus nerve, hypoglossal nerve, phrenic nerve and lingual nerve. Spinal accessory nerve injury causes difficulty in shrugging shoulders and shoulder hand syndrome. Hypoglossal nerve injury will cause tongue paralysis. Vagus nerve injury may manifest as aspiration and voice problems. Phrenic nerve injury causes paradoxical breathing and lingual nerve injury causes taste problems. Neuropraxia may recover within months; where as neurotemesis and axonotemesis have varying outcome.

\section{Carotid sinus syndrome}

This is due to undue pressure and manipulation on the carotid sinus baroreceptor which may result in hypotension and bradycardia. Post operative scarring may also make the receptor sensitive to even palpation and turning head.

\section{Pneumothorax}

Too much lower neck dissection may cause injury to the apical pleura causing pneumothorax. Patient may become restless, cyanosed and dyspnoeic after operation. A plain radiograph of chest most often provides the diagnosis. Minimal emphysema may resolve itself but whereas severe cases may require intercostal chest drains. 


\section{Intermediate complications}

Pulmonary complications

Basal collapse and bronchopneumonia may occur in patients who are smokers and have pre-existing chronic obstructive lung disease.

Deep vein thrombosis

This is seen in patients in old age, surgeries lasting for more duration, long bedridden patients and patients with previous history of deep vein thrombosis, pulmonary embolism, myocardial infarction and thrombophilia.

Chylous fistula

This happens due injury to the thoracic duct while performing a radical surgery low in the neck or mediastinum. If chylous fistula is suspected every attempt should be made to seal it at the time of surgery by identifying it by head down positions and performing modified valsalva manoeuvre. It should be suspected when the drain collection increases dramatically by volume. Fat restricted diet, and daily pressure dressings are the form of conservative treatment for chyle leak. When the drain collection reaches $600 \mathrm{ml}$ per day or more, it is an indication for exploration and repair of the injured thoracic duct under microscope.

Carotid artery rupture

This usually occurs when the skin wound breaks down because of previous irradiation, secondary infection, poor metabolic condition of the patient. It is a fatal complication resulting in immediate mortality if not intervened immediately. Control of bleeding by immediate finger pressure, airway management, blood transfusion and exploration in operation theatre has to be done.

\section{Late complications}

Recurrence

Recurrences can be at the primary site, in the neck nodes or as a distant metastasis.

Lymph edema

When both the internal jugular veins are ligated, lymphedema often follows owing to interruption of the lymphatic drainage channels from the head.

Hypertrophic scars

\section{Author's experience}

From year 1998 to 2011, the author has done over 250 neck dissections which included around 50 selective neck dissections and 200 comprehensive neck dissections. Out of the 200 comprehensive neck dissections, 75 were radical neck dissections and 125 were modified neck dissections. However if we look at the year wise distribution, we could clearly see a change in trend from radical neck dissection to less radical, modified radical neck dissection. 60 out of 75 i.e. $91 \%$ were done before year 2006 and 15 ie only $9 \%$ were done after 2006 .

A separate study has been done in year 2009-2010 by Bakshi et al which compared selective neck dissection with modified/radical neck dissection in terms of outcome and disease control in patients with carcinoma of buccal mucosa and also analyzed whether selective neck dissection can be used as a safe and effective treatment modality in N0 and N+ necks in cases of carcinoma buccal mucosa. The study included 22 patients who underwent 


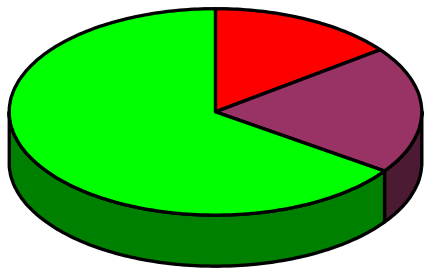

\section{$\square$ RND \\ MND \\ $\square$ SND}

Fig. 21. Number of neck dissections by author

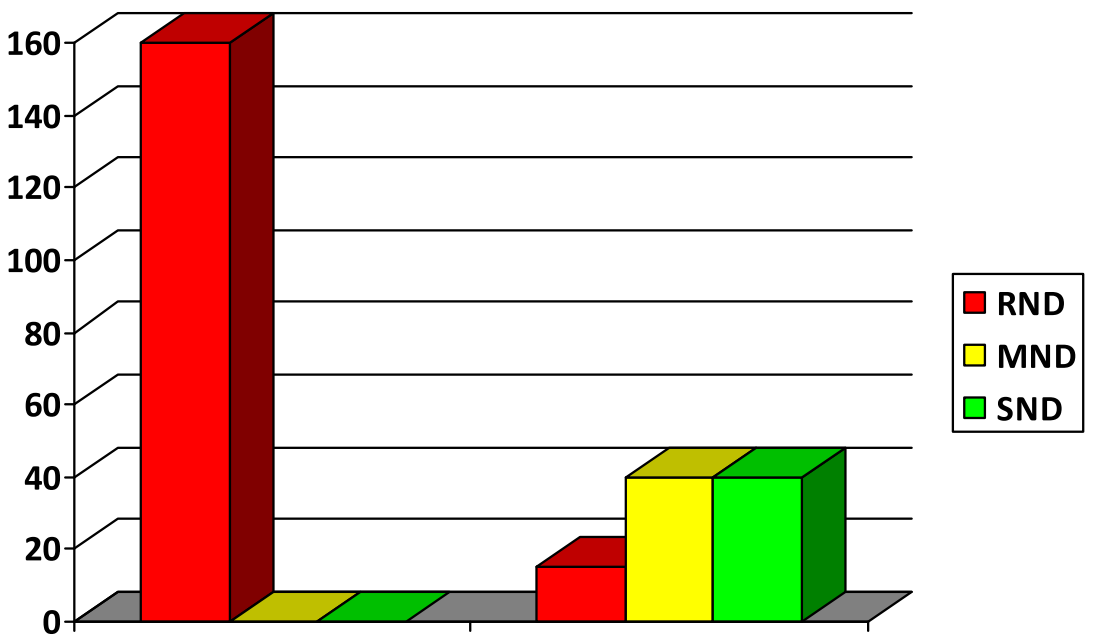

Before 2006

After 2006

Fig. 22. Year wise distribution of Neck dissections

modified/radical neck dissection and 20 patients who underwent selective neck dissection. It was seen that $16(38.09 \%)$ patients out of the total group of 42 patients, had recurrence/residual disease at the time of completion of study whereas the remaining 26 patients $(61.91 \%)$ were disease free for a minimum period of 6 months (ranging from 1224 months) with a mean follow up of 18 months. When studied group wise it was noticed that $9(40.90 \%)$ patients in Group A (RADICAL NECK DISSECTION/MODIFIED RADICAL NECK DISSECTION) had recurrence whereas only 7 (35\%) patients in Group B(SELECTIVE NECK DISSECTION) had recurrence. The difference between the number of patients with recurrent disease between the groups was not found to be statistically significant ( $p=0.790$ ). The study puts into perspective, selective neck dissection in the cases of carcinoma buccal mucosa, as a safe and effective modality for addressing the neck disease in both $\mathrm{N} 0$ and N1, $\mathrm{N} 2 \mathrm{a}$ and $\mathrm{N} 2 \mathrm{~b}$ necks with failure rate being comparable to that of radical/modified radical neck dissections. Hence patients can be spared from the morbidity of more radical procedures without compromising on the oncological safety. Most common lymphnode group involved in this study was level Ib followed by IIa. 
Another study done by the author which analysed the outcome of surgical treatment for squamous cell carcinoma of the oral cavity taking into consideration mode of presentation, histopathological aspects, treatment, recurrence, prognostic factors and survival in patients undergoing various surgical modalities for primary oral cancer and metastatic cervical nodes. The study included 80 patients and was done between 2001 and 2006. The study concluded that combined modality of treatment would be a better approach to deal with advanced oral cancer as it offers good loco regional control and survival rate. However, tumor size and extent, type and grade, the neck node status and the status of excision margins do affect surgical prognosis and survival rate.

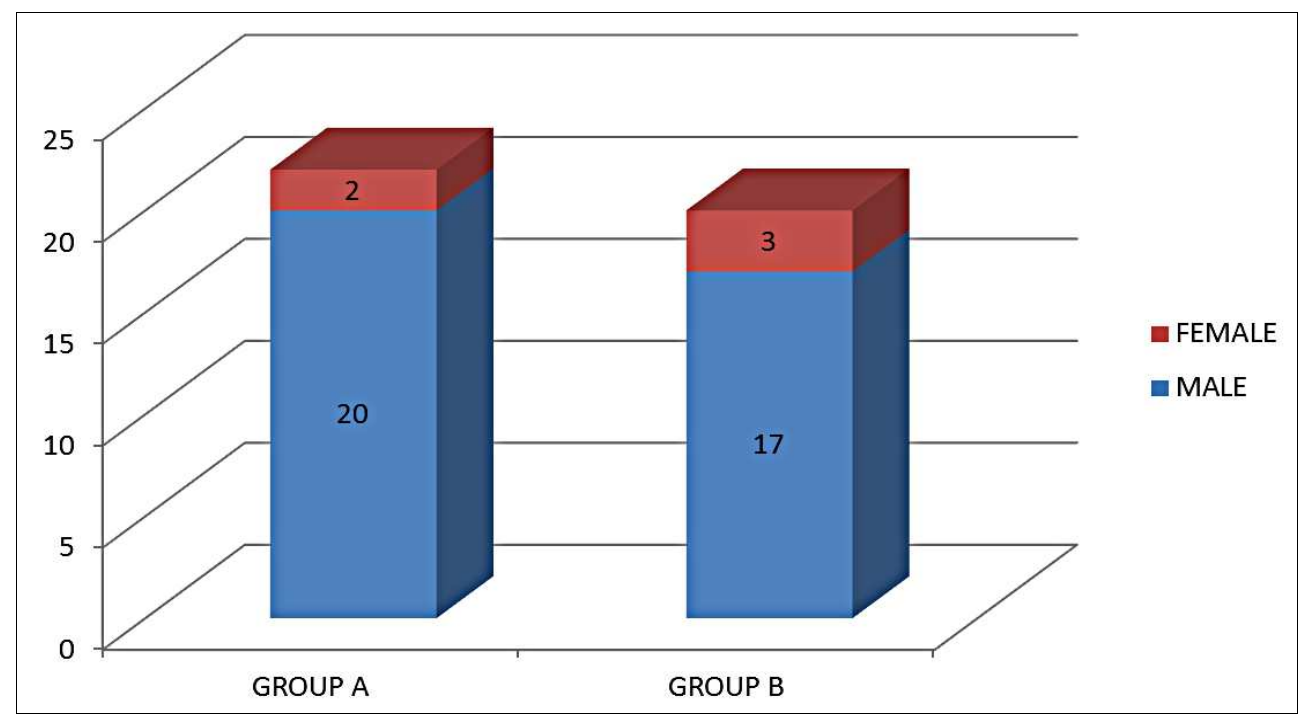

Fig. 23. Patient Distribution

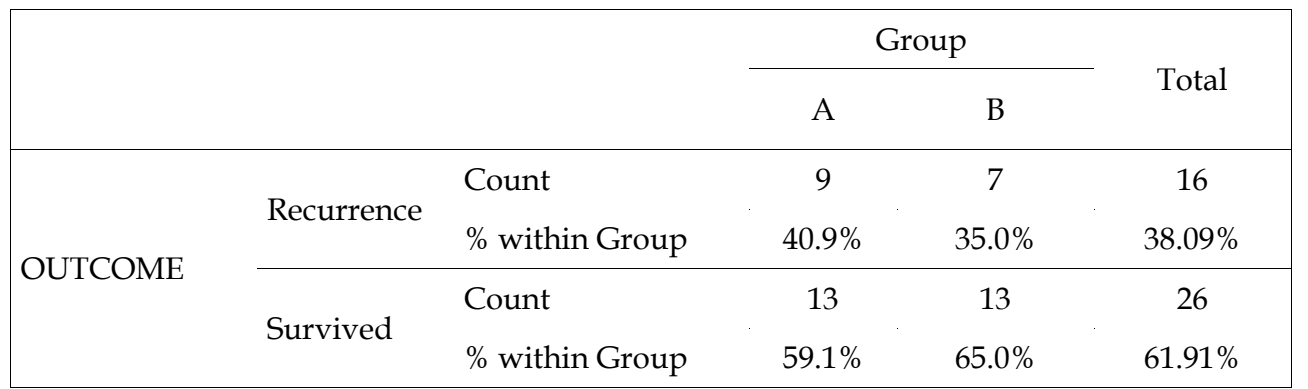

Table 1. Study results 


\section{Survival Functions}

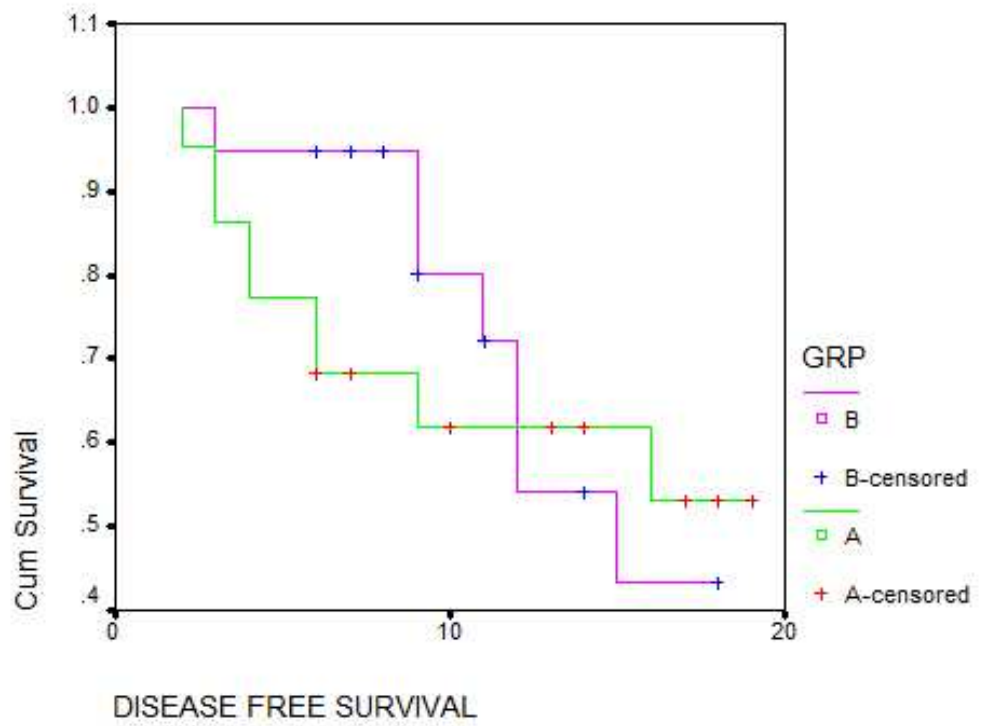

Fig. 24. Patient survival as calculated by Kaplan Meier method

\section{References}

Robbins KT. Classification of neck dissection: current concepts and future considerations. Otolaryngol Clin North Am. Aug 1998;31(4):639-55

Medina JE, Byers RM: Supraomohyoid neck dissection: Rationale, indication and surgical technique.

Head Neck 1989, 11:111-122

Shah JP: Patterns of lymph node metastasis from squamous carcinomas of the upper aerodigestive tract. Am J Surg 1990, 160:405-409.

Michael J. Gleeson Scott-Brown's Otorhinolaryngology: Head and Neck Surgery 7Ed, Chapter 199

Medina JE. Neck Dissection. In: Bailey BJ and Johnson JT. Head \& Neck SurgeryOtolaryngology. 2. $4^{\text {th }}$ ed. Chapter 113: Lippincott Williams \& Wilkins; 2006:15851609

Ashok R. Shaha Radical Neck Dissection. Operative Techniques in General Surgery, Vol 6, No 2 (June), 2004: pp 72-82

Javier Gavilan et al, Modified Neck dissection. Operative Techniques in General Surgery, Vol 6, No 2 (June),2001: pp 83-94 


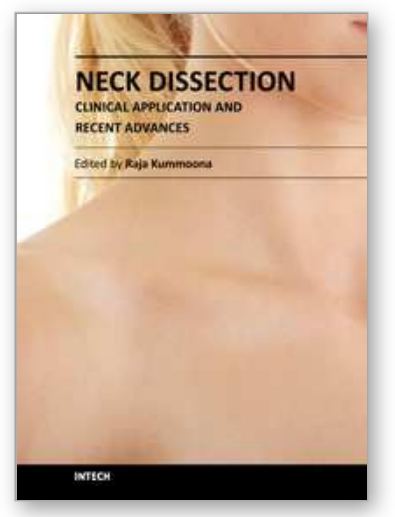

\author{
Neck Dissection - Clinical Application and Recent Advances \\ Edited by Prof. Raja Kummoona
}

ISBN 978-953-51-0104-8

Hard cover, 164 pages

Publisher InTech

Published online 22, February, 2012

Published in print edition February, 2012

Neck Dissection - Clinical Application and Recent Advances is a leading book in neck surgery and represents the recent work and experiences of a number of top international scientists. The book covers all techniques of neck dissection and the most recent advances in neck dissection by advocating better access to all techniques of neck dissection; e.g. Robotic surgery (de Venice) system, a technique for detection of lymph node metastasis by ultra sonography and CT scan, and a technique of therapeutic selective neck dissection in multidisciplinary treatment. This book is essential to any surgeon specializing or practicing neck surgery, including Head Neck Surgeons, Maxillofacial Surgeons, ENT Surgeons, Plastic and Reconstructive Surgeons, Craniofacial Surgeons and also to all postgraduate Medical \& Dental candidates in the field.

\title{
How to reference
}

In order to correctly reference this scholarly work, feel free to copy and paste the following:

Jaimanti Bakshi, Naresh K. Panda, Abdul Wadood Mohammed and Anil K. Dash (2012). Neck Dissection Techniques and Complications, Neck Dissection - Clinical Application and Recent Advances, Prof. Raja Kummoona (Ed.), ISBN: 978-953-51-0104-8, InTech, Available from: http://www.intechopen.com/books/neckdissection-clinical-application-and-recent-advances/neck-dissection-techniques-and-complications

\section{INTECH}

open science | open minds

\section{InTech Europe}

University Campus STeP Ri

Slavka Krautzeka 83/A

51000 Rijeka, Croatia

Phone: +385 (51) 770447

Fax: +385 (51) 686166

www.intechopen.com

\section{InTech China}

Unit 405, Office Block, Hotel Equatorial Shanghai

No.65, Yan An Road (West), Shanghai, 200040, China

中国上海市延安西路65号上海国际贵都大饭店办公楼 405 单元

Phone: +86-21-62489820

Fax: +86-21-62489821 
(C) 2012 The Author(s). Licensee IntechOpen. This is an open access article distributed under the terms of the Creative Commons Attribution 3.0 License, which permits unrestricted use, distribution, and reproduction in any medium, provided the original work is properly cited. 